goes further, setting improvement in the health and social functioning of mentally ill people as the first mental health target and proposing that success must be quantified. ${ }^{4}$ The limited development of information systems is impeding each of these aims.

Three issues underlie the slow progress in developing mental health informatics. Firstly, although community care has been long anticipated, the new configurations of services have emerged only relatively recently. A decade ago, with most care still being provided in hospitals scheduled for closure, investment in computer systems seemed premature. Secondly, the developing network of small and dispersed centres of care called for wide computer networks, which until recently were expensive and unreliable. ${ }^{5}$ Thirdly, and perhaps most significantly, the minimum datasets that managers have been required to collect have had little practical use and raised little enthusiasm. Based on the approach defined by the Körner review in the early. 1980 s, $^{6}$ the datasets treat mental health care as episodic and mainly based in hospital. The activity of each group of staff caring for outpatients is collated separately so that the extent to which they share care cannot be identified-even if the care is multidisciplinary the datasets are not.

The first two problems are now historical. The running down of most asylums scheduled for closure is well advanced and mental health services in the community are mostly in place (although facilities for social care are lagging behind). Linkages between remote computer systems are now cheap and reliable. The inappropriateness of the dataset therefore is the remaining impediment.

A dataset specifies what items of information are to be recorded and when this should occur. Two criteria determine a dataset's usefulness: it must contain the required facts, and information must be collected at convenient and logical points. It should, therefore, reflect the rhythm of staff activity. The present NHS dataset has two important omissions. Firstly, no details of care provided by local authorities or independent agencies are recorded even though these are key components in multidisciplinary community care. Secondly, standardised measures of medical and social problems-information needed for assessing both the process and outcome-are not included.

Two projects funded by the Department of Health should solve the second problem. The research unit of the Royal College of Psychiatrists is developing a scoring system (Health of the Nation Outcome Scale for routine clinical measurement of the health and social functioning of mentally ill people). ${ }^{7}$ In addition, the NHS Casemix Office is developing a new method of classifying mentally ill people by using diagnosis and problem scores, which should improve the prediction of needs for care ${ }^{89}$ Both projects use the same scoring system and provide information that should be included in a current clinical summary.

Until recently there has been no satisfactory way of specifying at what point in a patient's care a dataset should be collected. The rhythm of care in the old asylums had just two peaks: the admission of people who had become mentally ill and the discharge of those who had recovered. The move into the community started in a wide variety of ways in different places and muffled the clarity of that rhythm's beat. The care programme approach offers a new rhythm. Care proceeds from review to review, with key workers monitoring what happens in between. In simple cases reviews are conducted between the patient and a single professional. For more complicated problems multidisciplinary teams meet. Either way the pattern of assessment, care plan, keyworking, and reassessment is the same. Increasingly, pioneering provider units are developing information systems that collate care plans based on the reviews.

There are good reasons for the Department of Health to follow this lead and base its minimum dataset on reviews of care. The data would be relatively easy to collect; could cover all aspects of patients' care, including those provided outside the NHS; and should give staff useful lists and up to date summaries about their own patients. If held on an appropriate computer network the dataset would give ready access to the key facts needed in emergencies. It would also provide managers and purchasers with rich data on the number of patients, the nature of their problems, the care delivered, and its outcome. Everyone needs information, but it has to be useful and usable.

Department of Public Health and Primary Care,

GYLES GLOVER Senior lecturer

Chelsea and Westminster Hospital,

London SW10 9NH

Dr Glover is seconded part time to the Department of Health to work on the mental health minimum data set project.

1 Rohde PD, Taylor J. Computerised clinical case-record systems. In: Thornicroft G, Brewin C, Wing JK, eds. Measuring mental health needs. London: Royal College of Psychiatrists, 1992:237.

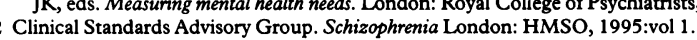

3 Department of Health. Health and social care development. "Caring for people." The care programme approach for people with a mental illness referred to the specialist psychiatric services. London: DoH, 1990. (HC(90)23/LASSL(90)11.)

4 Secretary of State for Health. The health of the nation. London: HMSO, 1992. (Cm 1986.)

5 McClelland R. An evaluation of two mental health information systems. Belfast: Department of Mental Health, Queen's University, 1992.

6 Steering group on health services Information. First report to the Secretary of State. London: HMSO, 1982. (Chair: E Körner.)

7 Wing J, Curtis R, Beevor A. 'Health of the Nation': measuring mental health outcomes. Psychiatnc Bulletin 1994;18:690-1.

8 Anthony P. Casemix in mental illness-current opportunities and problems. In: Anthony P, ed. Presentations from a conference at Birmingham Repertory Theatre, 14th fune 1994. London: Presentations from a conference at Birmingham Reperiony
Information Management Group, NHS Executive, 1994.

9 Horn SD, Chambers AF, Sharkey PD, Horn RA. Psychiatric severity of illness. A case mix study. Med Care 1989;127:69-84.

\title{
Functional dysphonia
}

\section{Not "hysterical" but still seen mainly in women}

Last year at the Glasgow Royal Infirmary over 190 new patients presented with dysphonia (hoarseness) and were referred to speech and language therapists for voice therapy. Extrapolation from these data suggests that up to 40000 such patients are referred and treated annually in Britain. A substantial proportion suffer from functional dysphonia, in which there is neither a structural abnormality of the larynx (such as a vocal cord polyp, nodule, or papilloma) nor paralysis. As with most functional somatic symptoms, women are considerably overrepresented, in some series by a factor of eight. ${ }^{1}$

Functional dysphonia is a diagnosis of exclusion. It may be confirmed only after specialist examination of the larynx by an otolaryngologist, which means that otolaryngologists see large numbers of patients with functional dysphonia in their outpatient practice. Traditional teaching dictates that hoarseness should remain "unexplained" for only three weeks, especially in smokers. 
General practitioners, however, are aware that laryngeal cancer is rare and found predominantly in older patients. Therefore, because most patients with functional dysphonia are young or middle aged adults who are otherwise healthy, roughly $40 \%$ are diagnosed presumptively as having laryngitis and receive a trial of antibiotic treatment before being seen as hospital outpatients.

There are two particular problems in diagnosis. The presenting symptom of altered voice quality is subjective, both for the patient and for the clinical observer. Secondly, as with many putative functional symptoms, dysphonia forms part of a range from a barely noticed variant of normality to a major life disability.

Broadly speaking, there are two types of functional dysphonia: disorders of hypofunction, with inadequate apposition of the vocal cords; and hyperfunctional dysphonia, in which accessory laryngeal muscles are used in voicing (this reaches its most extreme variant-dysphonia plicae ventricularis-in middle aged men who recruit the false cords in phonation). The disorder may also be classified according to the amount of residual phonation present: completely mute ("hysterical aphonia"), continually whispered speech, intermittently phonated "whispered" speech, or continually phonated speech. Rare variants of functional dysphonia include puberphonia or mutational falsetto, in which the voice retains an inappropriately high and monotonous quality into adulthood, ${ }^{2}$ and spasmodic dysphonia, which was long held to be of psychogenic origin but in recent years has been thought to be a focal dystonia. ${ }^{3}$

\section{Aetiology and treatment}

The role of psychosocial factors in the aetiology of functional dysphonia remains in doubt. Early psychodynamic explanations of hoarseness as a conversion symptom ${ }^{1}$ have given way to a search for characteristic personality traits. Dysphonic patients are more introverted and score higher on neuroticism scales than controls. ${ }^{4}$ This may be a non-specific personality diathesis shared with at least one other functional otolaryngological syndrome, globus pharyngis. ${ }^{5}$

Conversely, there is evidence that the environmental stressor may be a specific type of interpersonal difficulty: when the Bedford College life events and difficulties questionnaire was administered to a cohort of dysphonic patients $54 \%$ reported a recent life event involving "conflict over speaking out," compared with only $16 \%$ of a female control group. ${ }^{6}$ In a study which used structured psychiatric interviews a third of 71 patients with functional dysphonia received diagnoses of mood, anxiety, or adjustment disorders. ${ }^{7}$ Evidence that very few patients have personality disorders ${ }^{7}$ corrects an earlier influential report suggesting that most people with functional dysphonia have a "hysterical flavour."

Historical treatments of functional dysphonia included applying "stimulating" sprays to the vocal cords or electric currents to the cervical muscle or giving oral quinine, arsenic, or strychnia. ${ }^{8}$ Modern conventional treatment is speech therapy, which often includes training in relaxation. A recent British survey showed that speech therapists tend to acquire their psychological skills haphazardly, often after qualifying, and confirmed that voice therapy is far from standardised.9 Nevertheless, in the only controlled prospective trial reported to date, patients given a course of direct voice therapy which aims to improve voice production through vocal rehabilitation exercises showed a significantly greater return to normal voice functioning than untreated controls. ${ }^{10}$ Indirect therapy (which aims to improve patients' knowledge and awareness of the causes of voice disorder) produced intermediate results.

In patients who fail to respond to conventional voice therapy, additional psychological support with a cognitivebehavioural approach has been advocated. ${ }^{11}$ In the minority of subjects with hyperfunctional dysphonia, results equivalent to those achieved with relaxation therapy are claimed for a laryngeal electromyelographic biofeedback technique. ${ }^{12}$ Good results are also claimed for massage of the laryngopharyngeal area ${ }^{13}$ Neither approach, however, has been compared with a placebo or no treatment.

In psychosomatic medicine functional dysphonia provides a paradigm of the shift from intuition to objectivity. There has been progress in defining the disorder objectively; assessing the aetiological role of organic, psychological, and social factors; understanding the degree of accompanying psychiatric disturbance; and characterising the key therapeutic elements and effectiveness of speech therapy. None of these has been solved definitively. Even less is known about the prime mystery of this and other functional somatic syndromes-namely, the fact that most of the sufferers are women.

JANET A WILSON Professor

Department of Otolaryngology Head and Neck Surgery,

Freeman Hospital,

Newcastle upon Tyne NE7 7DN

IAN J DEARY

Professor

Department of Psychology,

University of Edinburgh,

Edinburgh EH8 9JZ

SHONAGH SCOTT

Research associate

KENNETH MacKENZIE

Consultant

Department of Otolaryngology and Head and Neck Surgery,

Royal Infirmary,

Glasgow G31 2ER

1 Aronson A, Peterson H, Litin E. Psychiatric symptomology in functional dysphonia and aphonia. foumal of Speech and Hearing Disorders 1966;31:115-27.

2 Hartman DE, Aronson AE. Psychogenic aphonia masking mutational falsetto. Arch Otolaryngol 1983;109:415-6.

3 Murry T, Cannito M, Woodson E. Spasmodic dysphonia. Arch Otolaryngol Head Neck Surg 1994;120:310-6.

4 Gerritsma EJ. An investigation into some personality characteristics of patients with psychogenic aphonia and dysphonia. Folia Phoniatrica and Logopaedics 1991;43:13-20.

5 Deary IJ, Wilson JA, Mitchell L, Marshall T. Covert psychiatric disturbance in patients with globus pharyngis. Brf Med Psychol 1989;62:381-9.

6 House A, Andrews $\mathrm{H}$. Life events and difficulties preceding the onset of functional dysphonia. $f$ Psychosom Res 1988;32:311-9.

7 House A, Andrews H. The psychiatric and social characteristics of patients with functional dysphonia. $\mathcal{F}$ Psychosom Res 1987;31:483-90.

8 Ingals EF. Hysterical aphonia, or paralysis of the lateral crico-arytenoid muscles. FAMA 1890;15:92-5.

9 Elias A, Raven R, Butcher P, Littlejohns D. Speech therapy for psychogenic voice disorder: a survey of current practice and training. British fournal of Disorders of Communication 1989;24:61-76.

10 Carding P, Horsley I. An evaluation study of voice therapy in non-organic dysphonia. European fournal of Disorders of Communication 1992;27:137-58.

11 Butcher P, Elias A, Raven R, Yeatman J, Littlejohns D. Psychogenic voice disorder unresponsive to speech therapy. Psychological characteristics and cognitive behaviour therapy. British foumal of Disorders of Communication 1987;22:81-92.

12 Andrew S, Warner J, Stewart R. EMG biofeedback and relaxation in the treatment of hyperfunctional dysphonia. British foumal of Disorders of Communication 1986;21:353-69.

13 Roy N, Leeper HA. Effects of manual laryngeal musculoskeletal tension reduction technique for functional voice disorders: perceptual and acoustic measures. Foumal of Voice 1993;7:242-9. 